Article

\title{
Trade in the Carbon-Constrained Future: Exploiting the Comparative Carbon Advantage of Swedish Trade
}

\author{
Hana Nielsen *(1) and Astrid Kander \\ Department of Economic History, Lund University, 22363 Lund, Sweden; astrid.kander@ekh.lu.se \\ * Correspondence: hana.nielsen@ekh.lu.se; Tel.: +46-46-222-03-45
}

Received: 26 May 2020; Accepted: 8 July 2020; Published: 14 July 2020

check for updates

\begin{abstract}
This paper introduces a new concept of comparative carbon advantage as a potential climate mitigation tool. According to the concept, welfare gains in terms of reduced global $\mathrm{CO}_{2}$ emissions can be achieved by exploiting cross-country sectoral differences in carbon intensity and decarbonized electricity system. The paper empirically tests the concept by utilizing annual data of Sweden between 1995 and 2008. Overall, the results show that Sweden contributed nearly 590 million tons of potential $\mathrm{CO}_{2}$ emissions savings through its exports by having an efficient and low-carbon production and electricity system. This total amount of 590 million tons of $\mathrm{CO}_{2}$ emissions relates to the total savings made if the same amount and composition of Swedish exports was produced using the world average technology. Furthermore, the contribution of Sweden's low carbon electricity generation was over $34 \%$ of the total savings, of which some $20 \%$ were direct exports of electricity and $80 \%$ was electricity embodied in exported products. This research provides a critical understanding of the impact of efficient production and low carbon electricity in generating relative comparative carbon advantage - a policy relevant aspect for the increasingly globalized, and carbon-constrained, world.
\end{abstract}

Keywords: foreign trade; comparative carbon advantage; carbon emissions

\section{Introduction}

Since the 1970s energy consumption has stabilized in Western Europe, while economic growth has continued [1]. Structural changes (away from heavy energy-intensive industrial production towards lighter industries) together with technological changes (efficiency in energy use) have been put forward as the proximate drivers of this decoupling, while the underlying (ultimate) reasons are open to debate. Ultimate reasons could be a natural shift over to more demand of services than industrial goods as countries develop [2], but it could equally well be a sign of the outsourcing of heavy industrial activities to emerging economies. Naturally, if developed countries live in the service economy and import their heavy industrial goods, the pollution problem is not solved but merely shifted around in the world. So what is the evidence on outsourcing? The magnitude of international trade has increased substantially and so has the amount of energy and emissions embodied in trade. Between 1970 and 2009, the global trade increased by some $7 \%$ annually [3]. Numerous studies emerged over the last decades to quantify the energy and carbon content of these increased trade flows. In general, most studies find that developed countries are net importers of embodied emissions while developing countries are net exporters [4]. Furthermore, production is often moved to countries that lack stringent environmental legislation and efficient modes of production, where relative carbon intensity is far higher than that of the developed countries. Clearly, this poses a threat to any ambitious global and national sustainability goals if this means that the developed world is shifting emissions to other non-regulated countries, rather than solving the urgency of global climate change. Still, the evidence is not clear cut on the outsourcing issue: the conventional way of measuring outsourcing has flaws because it overlooks that a significant part of what appears to be outsourcing is actually only different technology and energy 
systems [5]. In fact, for the period 2000-2014, 20 EU-countries and the US, emissions decreased over the period regardless of measure, and the same was true for the EU. Since Gross Domestic Product (GDP) grew in 18 of these countries, the results provide unambiguous evidence for absolute, albeit modest, decoupling of economic growth from carbon emissions [6]. Similarly, other research has found recently some evidence of both relative and absolute decoupling in a number of world countries [7]. The large increase in global emissions that nevertheless occurred during the period was driven almost entirely by increasing domestic consumption in China and developing countries. Still, international trade has the potential either to lowering the global emissions or to increasing them, depending on how that trade is organized; if it is climate smart or not.

Overall, the world is intensifying its efforts to reduce carbon emissions, though much of the efforts remain localized in a handful of regulated countries. The current absence of a global effort to curb greenhouse gas (GHG) emissions thus becomes increasingly problematic in a world with virtually free trade and carbon emissions embodied in traded goods. As a result, there is a danger that emission reductions in regulated countries with clear absolute reduction targets become offset (or exceeded) by emission increases in unregulated areas or areas with only relative carbon reduction targets. If this is the case, then any national efforts in lowering emissions may be undermined, and lead to an overall increase of global carbon emissions. So far, much attention has been devoted to the studies on the potential danger of carbon leakage [8-12]. However, trade does not only lead to geographical shifts in global production and structural change. Trade can also contribute to reduced global emissions if countries with access to low carbon energy and energy efficient production in goods that are normally associated with very high energy intensity, are the exporting parties. Thus national efforts can contribute positively to the global climate if production increasingly takes place in more carbon-efficient countries as this could potentially lead to a net decline in global emissions.

The major aim of this study is to quantify the magnitude of potential global carbon savings if trade patterns increasingly exploit national differences in carbon intensity in a climate smart way. The focus will be on the role of efficiency and decarbonisation of the energy system applied on the case of Sweden and its impact on the embodied emissions in its trade. Sweden is a particularly interesting example: a country with good access to cheap and virtually low carbon electricity, energy efficient production as well as substantial exporter of energy-intensive industrial goods. In 2008, the carbon intensity of the Swedish economy was one fifth of the European average carbon intensity and less than one tenth of the global average. We argue that this substantial difference in carbon intensity gives Sweden an absolute as well as comparative carbon advantage as opposed to other producing countries. It is beneficial for the global climate if heavy industrial production is located to Sweden rather than to other places. The major hypothesis is that countries with a comparative carbon advantage in a certain productive sector can have a beneficial effect on the global environment by increasing exports from this specific sector. Sweden, for example, with its ambitious environmental protection laws, could possibly contribute to welfare gains in terms of reduced global carbon emissions by exploiting differences in sectoral carbon efficiency through international trade. In this paper we show that Sweden contributed nearly 590 million tons of potential $\mathrm{CO}_{2}$ emissions savings through its exports by having an efficient and low-carbon production and electricity system. This total amount of 590 million tons of $\mathrm{CO}_{2}$ emissions represents the absolute savings made at a global scale if the same amount of Swedish exports was produced elsewhere using the world average technology (and world average carbon intensity). Furthermore, we find that the decarbonized electricity system accounted for over one third of the total savings, far more than for any other country. Contrary to most other papers, the role of trade is thus studied as a potential climate mitigation tool.

\section{Theoretical Considerations}

In general, there are two main mechanisms that can reduce the negative consequences of our energy use: making more economic use of the existing energy resources (efficiency) and gradual transition to low carbon energy resources (sustainable transition). A sustainable transition furthermore 
does not only involve the transition to a fossil fuel-free society but is also largely embedded in other areas, such as technological, social, institutional and economic change $[13,14]$. Yet, without any global emission reduction target it becomes problematic if these efforts to limit future emissions of greenhouse gases (GHG) remain constrained to a handful of countries, as trade may erase any improvements achieved. This research paper shows that trade, together with the predicted future increase in the global trade flows, can also be used as a climate mitigation tool. This is because of the theoretical potential to limit the global greenhouse gas (GHG) emissions if countries increasingly exploit the national differences in productive efficiency and carbon-intensity levels of its traded goods. This paper studies and quantifies the global environmental benefits of Sweden's foreign trade. The role of foreign trade as a possible emission reduction tool has rarely been explored in the past, but the continuous rise in emissions (and energy) embodied in foreign trade provides an important motive to study this phenomenon further.

\subsection{Efficient and Decarbonised Economy}

Historically, there have been substantial differences in the efficiency of global production, particularly in energy and carbon efficiency. After 1970, energy productivity differences across countries are larger than the differences in labor productivity [15]. Indeed, although there has been some degree of energy productivity convergence in world manufacturing sectors since 1970 and particularly after 1990s, the cross-country differences in the utilization of energy, and resources in general, remain larger than those in labor productivity [15-17]. The cross-country variations in energy productivity are often closely related to cross-country difference in carbon efficiency [18].

Decarbonisation of the economy is one of the prerequisites of meeting our climate objectives. Decarbonised economy (sometimes referred to as low-carbon economy (LCE) or low-fossil-fuel economy (LFFE)) is an economy generating much of its Gross Domestic Product (GDP) with the help of low-carbon energy resources and thus with a minimum level of $\mathrm{CO}_{2}$ emissions. The process of decarbonisation does not only 'require a reduction in the energy intensity of GDP, but also in the carbon intensity of GDP' [19]. Decarbonisation can be induced through increased energy efficiency, material efficiency and reducing the carbon intensity of the energy system (low-carbon energy production or carbon capture and storage (CCS)) [20]. It was thus proposed, that an increased electrification of the major energy-intensive processes could be one of the potential drivers of the decarbonisation of the economy. Previous research has shown that improvements in energy efficiency through applying best available technology in industry can potentially reduce the energy intensity by $20-25 \%$, before the limit for maximum energy efficiency is exhausted. Even though this represents potentially satisfactory levels of carbon efficiency, clearly other mechanisms will need to be employed. The increased deployment of bioenergy and the diffusion of the CCS technology have been explored in other studies as a potential to combat some of the carbon emissions [18]. Although the potential for savings has been found substantial for the four most energy intensive industrial sectors (cement, iron and steel, chemicals and paper and pulp) and in a range of 70-90\% reduction of the sectoral carbon emissions, the feasibility of this large-scale transformation remains uncertain.

In the light of this development, an attempt has been made to model the potential carbon savings if electricity is increasingly used in the energy and feedstock supply for the production of seven key basic materials in EU28 [20]. Clearly, for this to be beneficial in terms of carbon reductions much of the electricity must be produced using renewable sources. The authors argue that all energy and feedstock needs can be substituted by electricity produced from low-carbon sources and thus that the potential for future decarbonisation of the EU28 industrial sector is large [20]. Electricity can be regarded as the main future energy carrier in a decarbonized world. Although theoretically feasible, this additional electrification of the industrial processes would result in tremendously increased demands on electricity production and an integration and adaptation of the existing electricity system would be necessary. It would also entail 'substantial changes in relative prices for electricity and hydrocarbon fuels' [20]. 


\subsection{Absolute and Comparative (Carbon) Advantage}

The concepts of absolute and comparative advantage date back more than two centuries. According to Smith, a country has an absolute advantage if it produces and exports those goods which it can produce cheaper than other countries [21]. Comparative carbon advantage, on the other hand, relates to the opportunity costs of production and how these differ across countries, less so the actual absolute costs of production given the countries factor endowments. According to the Ricardian theory, it is mainly the relative differences in countries' abilities to produce goods and services that determine their pattern of trade [22]. Since certain production factors like natural resources or labor are less mobile than capital, countries can benefit from specialization in goods in which they are relatively more productive (have comparative advantage) and importing other goods where they lack this comparative advantage. Absolute and comparative advantages are not mutually exclusive. Countries can have comparative advantage in sectors where they do not have absolute advantage, yet the exploitation of their comparative advantage will lead to increased welfare gains. Sources of comparative advantage are often dynamic and complex, but usually a result of specific factor endowments required for the production, stemming from the constant interaction between the industries and countries and their ability to provide these requirements. Everything else equal, countries with weak environmental regulation tend to have a comparative advantage in polluting industries and tend to export relatively more from polluting industries [23]. On the other hand, decarbonized countries tend to have comparative advantage in 'clean industries'.

Increased trade involvement and specialization can, in turn, allow for increased economies of scale and further improvements in its comparative advantage, the so called 'gains from trade'. Gains from trade can be both static as well as dynamic. Static gains from trade according to comparative advantages are unevenly distributed among the trading partners. This idea relies on Ricardo's idea of trade according to comparative advantages which will lead to systemic gains: overall productivity in the system will go up, and the extra production will be shared among the trading partners. There will be internal losers and winners inside the countries, but all nations will gain from trade to some degree. Dynamic gains from trade do not stress the role of trade per se, but rather innovations and structural change within nations as a result of increased trade involvement. What matters for economic growth and development is diversification of the economy, technological development and labor productivity, rather than trade per se. If trade contributes to diversification and technological change it is good for the nation; if not, it is bad.

Absolute advantage in carbon efficient production—one that is characteristic for countries such as Sweden-is often seen as a costly measure and in a sense not an advantage when compared to other countries as the additional costs for low-carbon technologies may lead to the loss of competitiveness in the international markets, as long as there is no globally enforced tax on carbon emissions. Climate change is largely an externality to the economy and not priced into decisions or trade patterns. But this situation is gradually changing. An increasing number of countries in the world are pricing carbon emissions. Around the world, almost 60 carbon pricing initiatives had been implemented in 2018 , or were scheduled for implementation, covering about $20 \%$ of global greenhouse gases [24]. Many countries have individually determined carbon taxes on goods and consumption that cannot easily move abroad, such as gasoline for driving one's car. These taxes are in some cases very high, like in Sweden of about 1000 SEK/ton or reasonably high like in British Columbia of 40 dollars per ton (in 2019). In other cases, like India it only amounts to a few dollars per ton.

Not even with carbon cap and trade schemes (such as EU-ETS), will more carbon efficient production always be better positioned due to oversupply of the emission allowances (given the uncertainties in the future emissions) and consequently low carbon prices. To limit the competitiveness effect and prevent carbon leakage in the absence of realistic carbon prices, several instruments have been proposed. A climate club of more ambitious countries putting up carbon tarrifs against others has been proposed as a reasonable way forward $[25,26]$. Border Carbon Adjustments (BCA) have flooded the political debate in recent years. Although some argue that border carbon adjustments 
(BCAs) may result in trade wars while having only a very limiting impact on the global climate gains, other proponents highlight the ability of BCA to enhance the competitiveness of domestic firms, especially energy-intensive and trade-exposed industries [27]. Imposing border carbon adjustment on certain goods would then lead to additional costs and make the European market less attractive to a number of countries given their high energy intensity. A simulation exercise has shown that the total sales of EU firms (to domestic and foreign consumers) increase if border carbon adjustment (BCA) measures are implemented as opposed to situation without such measures [28]. On the other hand, there are some significant re-distributional effects associated with BCAs as changes in the terms-of-trade against the developing world shift the burden of emissions abatement to developing countries which in turn further intensifies existing income inequalities [29]. BCAs are also a politically sensitive topic, and possibly not compatible with World Trade Organization (WTO) rules on free trade [29-32]. Certainly a uniform carbon tariff or global carbon tax has been discussed as more optimal option-likely to be compatible with the WTO rules than border carbon adjustment (BCA) tariffs that differentiate between exporting countries [30], but this first best solution is so far from being realistic to impose that actually border carbon adjustment is a prominent feature of Europe's Green Deal, launched by Ursula van der Leyen in December 2019 [33].

The concept of comparative carbon advantage entails very much the same characteristics as that of comparative advantage. In a cross-country study of comparative advantage in polluting industries, Broner and colleagues found that countries with weaker environmental regulation export relatively more in polluting industries [23]. The authors find the impact of environmental regulations to be important and comparable in magnitude to traditional sources of comparative advantage such as skill and capital [23]. Against this, the concept of comparative carbon advantage is a result of the interaction between industries and the governments yet conditioned upon the availability of factor endowments in relation to other countries. Importantly the gains from specific factor endowments (such as low-carbon electricity) are exploited only in conjunction with stringent environmental regulation and national climate targets.

In the Swedish case the sources of comparative carbon advantage could be summarized as a dynamic interaction between the legislative forces and industries (stretching for number of decades), together with the availability of relatively cheap and low-carbon electricity. Effective interaction between the industry and the government can thus be seen as an important aspect of the comparative carbon advantage, through for example reduction of the transaction costs. This is because this interaction precedes the actual firms' decision on industrial location by establishing the renewable infrastructure and designing efficiency frameworks, but also at a later stage regulates other further environmental consequences of the increased concentration of energy intensive sectors (such as hazardous waste et cetera).

The role of electricity has been especially important in the case of Sweden. Historically, Sweden has had some of the world's lowest electricity prices with a bulk of electricity produced in carbon-free hydropower and nuclear power plants. This has contributed to the competitiveness of Swedish electricity-intensive industries in an international perspective. Comparative carbon advantage thus relates to the differences in cross-country carbon efficiency of production. In terms of comparative carbon advantage, the further electrification of the Swedish industrial production would likely be an important driver of the increases in the comparative carbon advantage. Other example of a country which exploits its comparative carbon advantage is Iceland. This small, export-driven economy in the Atlantic Ocean has access to hydro and geothermal power and has used this specific factor endowment for aluminum smelting. In fact, in Iceland aluminum smelting accounts for up to $90 \%$ of total electricity consumption. The flow of foreign investments in aluminum smelting was, however, still very much a result of government negotiations and bargaining starting already during 1960s [34]. 


\subsection{Environmental Policy and Competitive Advantage}

Commonly, stringent environmental regulation has been perceived as having detrimental properties on the levels of global competitiveness. Environmental regulations impose costly adjustments, often leading to slower productivity growth and reduced competitiveness in the international markets [35]. Forcing companies to adapt to more stringent rules and limit the amount of negative externalities produced has been perceived as a driver of reduced profits [36]. This has been a common belief among academics and policy makers until the publication of, what has since then been referred to Porter's hypothesis (1991). In the past, Porter not only pioneered the field of global comparative advantage, but his 1991 contribution to the magazine Scientific American radically transformed the field. According to Porter, 'strict environmental regulations do not inevitably hinder competitive advantage against rivals; indeed, they often enhance it', yet the evidence remains mixed [37]. In Sweden, assessing the static and dynamic effects of environmental policy on productivity among industries has led to mixed results [38]. Win-win solutions have been stressed by Lindmark and Bergquist [39], Bergquist and Söderholm [40] and Bergquist et al. [41], but also efficiency losses (win-lose) by Broberg et al. [42]. It seems however that regulations generally have had a positive effect on innovation and efficiency in Sweden [38].

Carbon tariffs are intended to discourage emissions of carbon in foreign-produced goods by placing additional tariffs on goods imported from mainly unregulated areas (countries delayed in the adoption of environmental legislation). Among highly regulated countries, carbon tariffs represent a popular policy instrument as it offers a way to "protect the competitiveness of energy-intensive, trade-exposed industries" [43].

\subsection{Exploiting Carbon Efficiency under Changing Trade Patterns}

Optimal resource allocation and its consequences for the global $\mathrm{CO}_{2}$ emissions have been studied in the past. Fujii and Managi assessed the $\mathrm{CO}_{2}$ emissions reduction potential for 13 manufacturing sectors in 39 countries between 1995 and 2009. More effective resource reallocation would imply that firms can relocate their production to countries that are more carbon efficient, which will reduce the global carbon emissions. Through the application of a Data Envelopment Analysis (DEA) model, the authors calculate the optimal level of resource reallocation on $\mathrm{CO}_{2}$ emissions and quantify the potential $\mathrm{CO}_{2}$ savings if production was reallocated to the most efficient countries. This exercise has shown that applying optimal production resource reallocation has a reduction potential of $2.54 \mathrm{Gt}-\mathrm{CO}_{2}$ in the year 2009. The largest potential to reduce $\mathrm{CO}_{2}$ emissions was then identified in the case of former communist countries; in sectoral analysis the potential was the largest in basic material industry including chemical and steel sectors [44].

Shifting trade patterns in order to reduce global carbon emissions was also studied by Strømman et al. [45]. The authors find that in a global model with tighter carbon constraints, some production located in carbon intensive economies would move out, as countries lose their comparative advantage to economies using cleaner fuels and/or more energy efficient technologies.

Clearly, a follow up question arises as to what extent production resources reallocation is realistic in the global world. This is because any large scale reallocation of a country's production will have numerous dynamic effects on the overarching economic structures, in particular social implications in form of increased unemployment or incomes from corporate taxation [44]. Also, the increased production concentration in some countries might lead to growth in trade and thus an overall increase in trade-related $\mathrm{CO}_{2}$ emissions. Last, the study does not include the electricity sector from being traded, either directly in exports of electricity or indirectly as electricity embodied in the manufacturing goods. As the empirical results of this paper show, this omission might change the overall results especially for countries with fossil-fuel based electricity transformation sector, as electricity intensity of some manufacturing sectors is very high. For example, the production of electronic goods primarily uses electricity as one important input factors, though in the traditional accounts of carbon intensity $\left(\mathrm{CO}_{2}\right.$ emissions/produced unit) related to the actual production of the electricity are not considered. 


\section{Methods and Data}

There are two mainstream approaches to account for carbon emissions at a national level. The production-based account, which is based on emissions within a country's borders and the consumption-based account, which holds the final consumers responsible for all upstream emissions caused by the production of a good regardless of where the emissions occur in the world. Besides traditional production-based accounts (PBA) and consumption-based (CBA) approaches, some versions of shared responsibility between producers and consumers have been launched [46-48]. As a result of the continuous expansion of global trade and its impact on the global carbon emission levels, researchers have ventured into integrating carbon emission transfers into the actual policy-making [49]. However, the current UN emission scheme remains confined to only those emissions which were incurred during the production process within a country (production-based accounts: PBA) [50].

\subsection{Consumption-Based Approaches}

Although there have been heated debates around the need for new measures of national carbon accounting which would take into account the country's actual consumption pattern (CBA), climate negotiations targets remain set to production-based accounting methods (PBA). The major drawback of the production-based (PBA) perspective is the fact that it encourages displacement or carbon leakage as countries simply relocate part of their production abroad. At the same time, countries producing export goods are being penalized for doing so [51]. Additionally, as empirical evidence has shown, this relocation of carbon-intensive production to the often emerging economies can lead to even larger emissions, as developing countries are more likely to lack the more energy and carbon efficient technologies of the developed world. This difference in energy and carbon intensity between countries does not only raise the global carbon emissions, but also penalizes countries with 'cleaner' production and stricter environmental regulation [48].

\subsubsection{Shared Responsibility Addressing the Blind Spot of Export Technologies}

The method employed in this paper departs from the consumption-based approach (CBA) of carbon accounting but addresses the weakness it contains: the blind spot of export technologies which countries clearly can take responsibility for. According to traditional consumption-based method (CBA), countries should not only be responsible for the emissions of their domestic production but also for the emissions embodied in imports which are then consumed domestically. But they do not need to take any responsibility for their export technologies. The introduction of consumption-based (CBA) approach was largely due to the fact that policy makers and academics became concerned about the absolute improvements in domestic carbon emissions and were puzzled to what degree these domestic improvements are due to carbon leakage to other countries. The basic formula of the CBA approach thus considers the flow of $\mathrm{CO}_{2}$ emissions which are finally consumed within a country and is a sum of territorial emissions or PBA (production-based emissions) and emissions embodied in imports, from which emissions embodied in exports are deducted:

$$
C B A^{S}=\sum_{i} f_{s}^{i}+\sum_{i, r \neq s} q_{i}^{r} \neq x_{i}^{r s}-\sum_{i, r \neq s} q_{i}^{s} \neq x_{i}^{s r}
$$

where $f_{s}^{i}$ refers to direct emissions, $q$ is an emissions multiplier, $\neq$ is elementwise multiplication, $x_{i}^{s r}$ is the output from production sector $i$ in country $s$ that is produced for final consumption in country $r$.

The emissions multiplier is then calculated simply by dividing the direct emissions with total output allocated amongst all final consumers for the relevant sector as shown in Equation (2). According to Equation (2), $y$ is defined as a collection of final demand bundles and $\mathrm{L}$ is the classical Leontief inverse, $L=\left(I-Z \hat{k}^{-1}\right)^{-1}$, where $I$ is the identity matrix, $Z$ is a multi-region input-output table of 
economic flows between countries and sectors, $\hat{k}$ is the diagonal of $k$, and $k_{i}$ records gross output of sector $i$.

$$
q_{i}^{s}=\frac{f_{i}^{s}}{\sum_{r} x_{i}^{s r}}=\frac{f_{i}^{s}}{\sum_{j, t} L_{i j}^{s t} y_{j}^{t r}}
$$

The major advantage of this approach is the fact that countries are now also made accountable for the emissions embodied in the importation of goods which are then consumed domestically. Obviously, this is a very valid concept which shifts responsibility onto the final consumer. Consumption can then be seen as one of the potential factors which nations can influence, either through changes in absolute volumes or its composition. However, as [48] has shown, although the consumption-based (CBA) concept captures the changes in domestic consumption which a nation can influence, it does not capture a country's efforts to improve its domestic carbon efficiency for exports (only efficiency improvements that relate to domestic consumption). In the CBA concept, thus, two countries trading identical product (let's say one ton of steel) may look entirely different in the balance of emissions in trade. Sweden, an example of energy efficient low-carbon economy produces one ton of steel with considerably lower $\mathrm{CO}_{2}$ emissions than for example China. If those two countries, Sweden and China, only trade in one specific good and exchange equal amounts of steel, Sweden becomes a net carbon importer while China will be a net carbon exporter. In this respect, energy and carbon efficient Sweden would be penalized for exporting its carbon efficient steel as its CBA carbon balance would be larger than its PBA emissions (and conversely for China where responsibility for inefficient carbon-intensive steel production was shifted onto Sweden). Therefore, Kander et al. [48] developed an adjustment to the traditional CBA accounting of emissions to accommodate for technology differences between countries. In the adjusted CBA framework (the technologically adjusted CBA or TCBA), the emissions multiplier is calculated using the world average technology instead of the specific carbon intensity of the domestic production (for a more elaborate discussion of the method see Supplementary Information of Kander et al. [48]):

$$
T C B A^{s}=\sum_{f} f_{i}^{s}+\overbrace{\overbrace{i, r \neq s} q_{i}^{r} x_{i}^{r s}}^{\text {net trade balance }}-\underbrace{\sum_{i, r \neq s} \dot{q}_{i}^{r} x_{i}^{s r}}_{\text {exports }}
$$

where the emissions multiplier is calculated by the expression $\dot{q}_{i}=\frac{\sum_{s, r \neq s} q_{i}^{s} \neq x_{i}^{s r}}{\sum_{s, r \neq s} x_{i}^{s i}}$.

The use of world average technology (and thus world average emissions) can be understood as emissions which would have occurred if the traded good was not produced in a specific country. For countries like Sweden which have an efficient and low-carbon production the amount of emissions embodied in exports would therefore increase (as world average carbon intensity is higher than Swedish carbon intensity). Higher volumes of emissions in exports would then, following the Equation (4), lead to lower balance of TCBA. Conversely, for countries with polluting production (more than the world average), the level of TCBA would then increase.

The difference between the newly computed TCBA and the traditional CBA approach has been named NEGA emissions [48]:

$$
N E G A_{i}^{s}=C B A_{i}^{s}-T C B A_{i}^{s}
$$

NEGA is a measure of global emissions that have not occurred as a result of production being located in a less, instead of a more, carbon-intensive country. NEGA emissions can be both positive (credits) when production is located in countries with better than world-average technology, as well as negative (penalties). Negative NEGA emissions are extra emissions generated because of the production being located in countries with worse than average technology. These EXTRA emissions are than penalties that can be assigned to the respective countries for having either inefficient production or fossil-fuel dependent energy system or both. In the above mentioned comparison of Sweden and China, Swedish technology-adjusted carbon accounts (TCBA) would be lower than its consumption-based 
accounts (CBA) and Sweden would receive NEGA credits (a 'reward' for having a better than world average carbon efficiency in the production of steel). China, on the other hand, would be held responsible for its carbon intensive production of steel for exports (more carbon intensive than the world average) and its technology-adjusted consumption accounts (TCBA) would be higher than the traditional consumption-based (CBA) approach. China would therefore receive EXTRA emissions compared to CBA approach, a penalty for not cleaning up its export sector. Importantly, to avoid double calculation of international trade, imports are treated differently than exports. As in the conventional consumption-based (CBA) approach, countries must take full responsibility for all the emissions related to their imports. But countries only take responsibility for carbon intensities of their export industries in relation to similar industries in the world, so in the technology-adjusted consumption accounts (TCBA) model the sum of all NEGA credits and EXTRA penalties at a global scale equals 0 , and the sum of all nations' consumption-based accounts (CBA) equals a sum of all nations' technology-adjusted consumption based accounts (TCBA). This is an important criterium and the method does not change the volume of global $\mathrm{CO}_{2}$ emissions, but instead redistributes the NEGA credits and EXTRA penalties geographically. Figure 1 shows visually the results of the new technology-adjusted carbon footprints for Sweden.
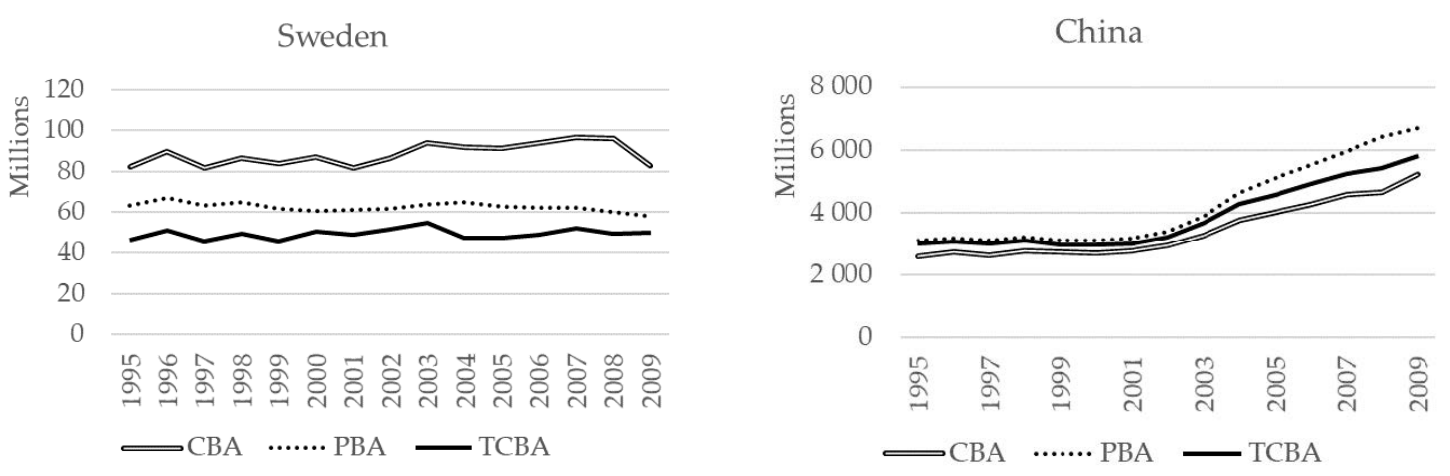

Figure 1. Technology-adjusted $\mathrm{CO}_{2}$ footprints (TCBA) of Sweden and China compared to national territorial emissions (or production-based account: PBA) and national carbon footprints (or consumptionbased accounts: $\mathrm{CBA}$ ). Note: million tons $\mathrm{CO}_{2}$ emissions.

In the case of Sweden, the difference between consumption-based accounts (CBA) and technology-adjusted consumption accounts (TCBA) is positive and Sweden thus has NEGA credits for its relatively efficient production. In other words, the amount of the NEGA credits corresponds to the amount of emissions which did not occur owing to the Swedish comparatively more climate-efficient exports. It is a theoretical assumption with the same global demand as in reality, but since Sweden did not produce the exported goods, the same volume of goods would be produced elsewhere. Since we cannot know where it would take place, the assumption is that any exporter on the world market might replace Sweden, and this unknown party is represented by the use of a weighted world average technology for each sector.

\subsubsection{NEGA Credits with Electricity}

An initial investigation into the sectoral composition of NEGA credits in Swedish exports, however, assigns the largest contribution to the electricity transformation sector. This is because electricity sector is treated as any other productive sector, though much of its production is channeled further in the production of final goods/exports.

Within a traditional input-output (I-O) framework, the largest share of improvements in electricity generation is assigned to the utilities sector. This is because electricity assigned to other sectors such as paper and pulp or iron and steel only includes direct emissions, whereas emissions embodied in the actual electricity generation (the indirect emissions) are allocated to the electricity generation sector. As a result, efficiency gains in electricity generation are visible primarily in the utilities sector while 
gains from electricity use in the manufacturing sectors and others remain understated. This may be a problematic assumption when quantifying gains from electricity consumption in the Swedish industry and its exports; also as discussions about the increased electrification of industrial processes emerge as a potential emissions reduction tool [20]. To address this issue, indirect emissions of electricity generation were redistributed to each economic sector in order to capture the combined emissions of each sector (see Figure 2). Simultaneously, the same proportion of carbon was deducted from the electricity generated as total emissions of the Swedish economy needed to remain equal after redistributing emissions to the final consuming sectors.

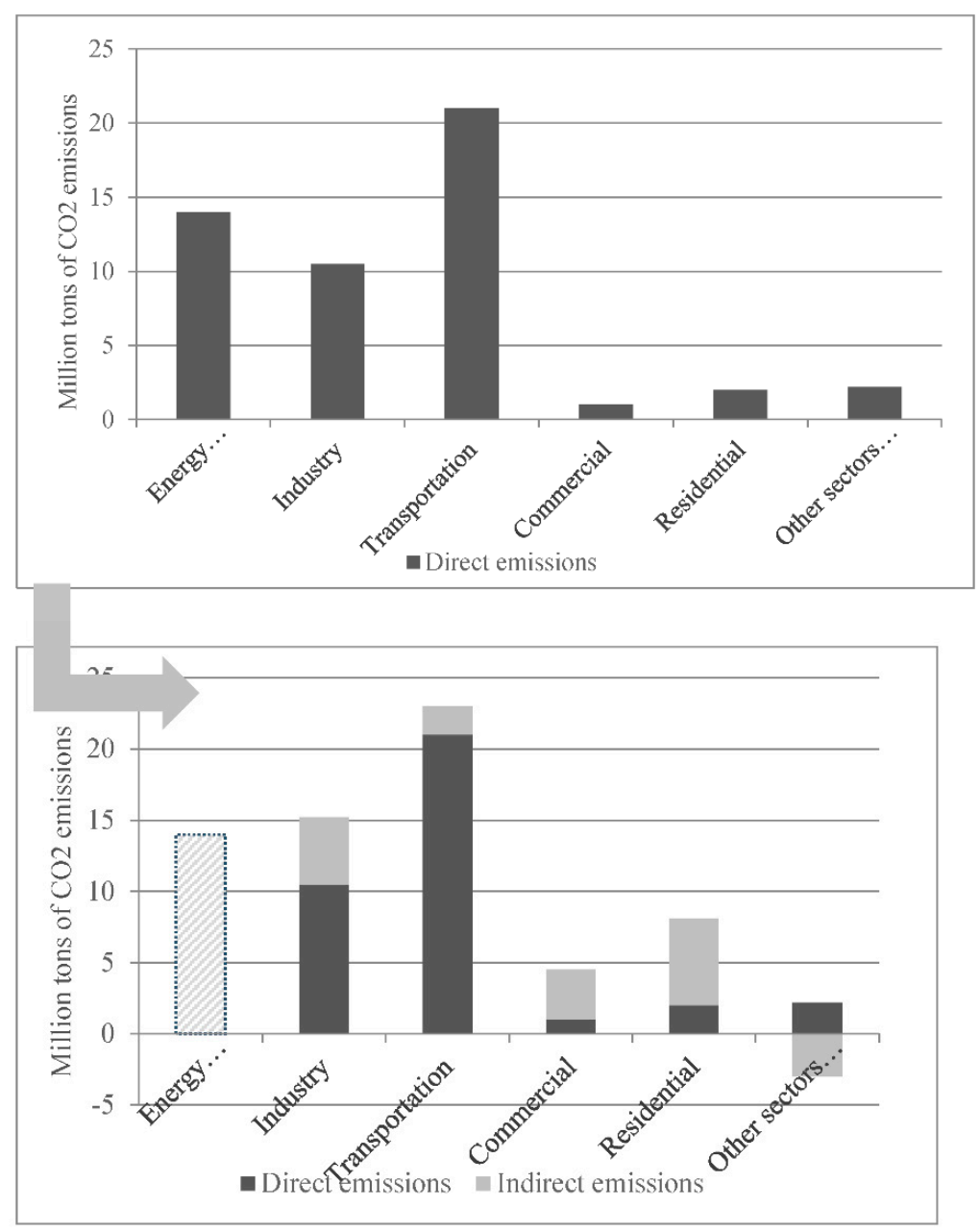

Figure 2. Re-distributing emissions from the utilities sector to the productive sectors (an illustrative example based European Energy Agency data).

To capture the real contribution of Swedish low-carbon electricity generation, the NEGA credits from the electricity production sector were redistributed to the respective productive sectors following:

$$
N E G A_{i}^{s}=N E G A_{i}^{s}+\sum_{i, r \neq s} N E G \dot{A}_{\text {elect }}^{r} \neq x_{i}^{r s}
$$

where $N E G A_{i}^{s}$ is the previously defined measure of global emissions that have not occurred as a result of production being relocated to a less, instead of a more, carbon-intensive country and which are the sum of the direct NEGA emissions which occurred at the individual productive sector and the secondary NEGA $A_{\text {elect }}^{r}$ emissions which are a result of the Swedish carbon-free electricity production and which are assigned to the specific consuming sectors. Overall NEGA emissions, be it from direct 
primary energy sectoral consumption as well as from the electricity sectors can be both positive (credits) as well as negative (penalties) depending on the specifics of the national energy system.

The reallocation of the NEGA credits from the electricity transformation sector to the productive sectors had two major consequences (see Figure 2 that visualizes the process of reallocation):

(1) The volume of the NEGA credits from the electricity generating sector decreased substantially. The remaining NEGA credits which can still be seen reported are NEGA credits embodied in the direct exports of electricity, so only foreign sales of Swedish produced electricity (here the final product is the electricity, and not a product with embodied electricity as is the case for the remaining sectors).

(2) On the other hand, other productive sectors increased their absolute volumes of NEGA credits, which is a sum of NEGA credits stemming from the primary energy consumption and the NEGA credits from the outsourced/purchased in electricity (electricity derived NEGA credits).

\section{Results}

\subsection{Total NEGA Emissions Saved}

Within the whole period of 1995-2009, the amount of emissions saved reached a cumulative total of nearly 590 million tons of $\mathrm{CO}_{2}$, emissions that would have been otherwise released into the atmosphere if the same amount of production occurred using the world average technology instead of the specific Swedish production system. This cumulative total is a sum of annual NEGA credits (or emissions saved) as visualized in Figure 3. On average, Sweden has saved 39.2 million tons of $\mathrm{CO}_{2}$ emissions each year between 1995 and 2009 with the year 2008 recording the absolute highest levels of over 46 million tons of $\mathrm{CO}_{2}$ emissions. To put this into perspective, the cumulative volume of 590 million tons of $\mathrm{CO}_{2}$ (which were prevented between 1995 and 2009) can be compared to the total $\mathrm{CO}_{2}$ emissions of EU28 in 2018 which was over 3460 million tons of $\mathrm{CO}_{2}$, so roughly $17 \%$ of the yearly total. This represents a relatively high share considering the fact that Swedish economy accounts for roughly $3 \%$ of the European GDP (Eurostat, 2019). Figure 3 shows the annual developments in total NEGA credits and the share of which that can be attributed to the Swedish carbon-free electricity embodied in produced goods. The decline in the total amount of NEGA credits in 2009 is entirely due to the drop of volumes of Swedish exports as a result of the global financial crisis. The growth of annual NEGA emissions between 1995 and 2008 has been then primarily driven by the increase in export volumes [52]. Overall, the volumes of exports have been increasing but accelerated especially after 2002 with 2008 being one of the record years for Swedish exports. The year 2009 brought about disruptions to the volumes of Swedish exports due to the international financial crisis and this is also a major reason for why we have omitted this year from certain parts of the analysis.

\subsection{Comparative Carbon Advantage in an International Perspective}

Figure 4 illustrates how Sweden compares to other countries in respect to total NEGA credits and the contribution of the electricity sector to the total NEGA credits. Negative signs for certain countries can be interpreted as NEGA penalties, where respective countries exported goods manufactured with worse than world average technology. Within the concept of NEGA credits, countries can thus be penalized for not having carbon efficient production and this is then reflected in the negative values for the obtained NEGA credits. 


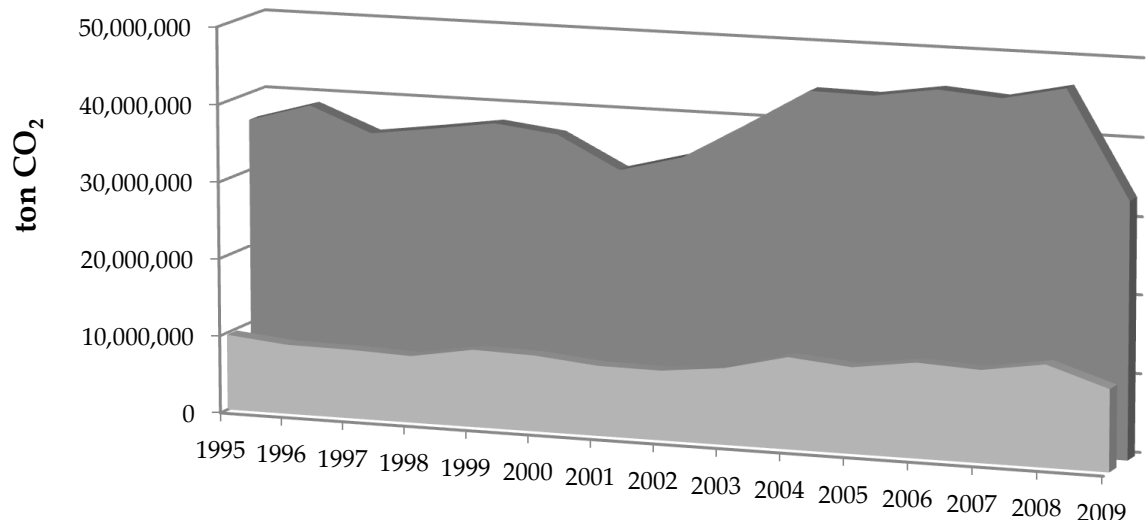

Electricity NEGA credits

- Total NEGA credits

Figure 3. NEGA credits in the Swedish exports (total NEGA) and of which embodied NEGA credits from electricity consumption (electricity NEGA).
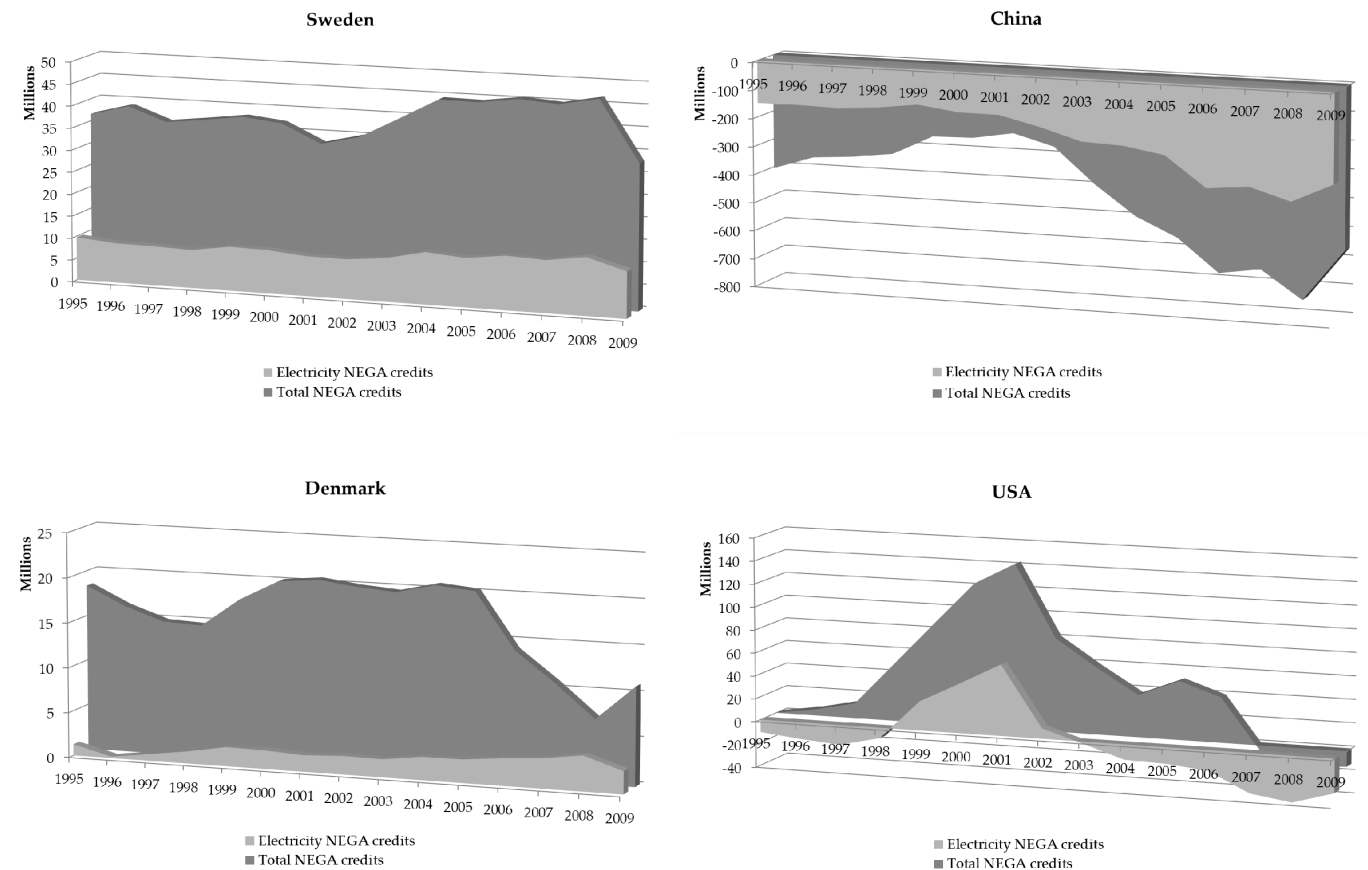

EU

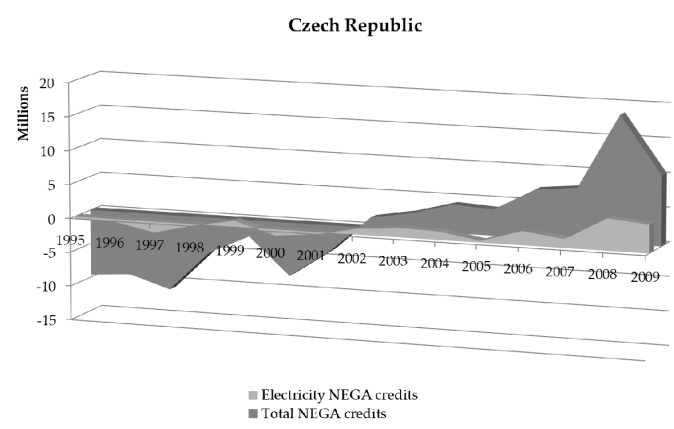

Figure 4. NEGA credits in exports (total NEGA) and embodied NEGA credits from electricity consumption (electricity NEGA) in a comparative perspective, in $\mathrm{M}$ tons of $\mathrm{CO}_{2}$ emissions. Note: Negative NEGA credits correspond to 'penalties' for having worse than world average carbon efficiency. The scale of the $y$-axis differs by country. 
Generally, in line with previous research $[6,48]$ European countries have on average more carbon efficient production and this can be seen in the relative surplus of NEGA credits. On the other hands, countries differ to what extent these NEGA credits can be attributed to low-carbon electricity production. Sweden has, for example a relatively significant proportion of NEGA credits in exports due to its specific electricity production system (between 26 and $28 \%$ of all total NEGA credits in 1995-2009). Denmark and Germany, on the other hand also generate NEGA credits but less so due to their higher carbon emitting electricity sectors. The share of electricity in the total NEGA credits was on average $11 \%$ in Denmark and $21 \%$ in the EU throughout the period of study. One exception is the year 2008, where temporarily electricity's contribution to the total NEGA emissions increased to over $50 \%$, both driven by drastic decline in NEGA credits from primary energy consumption and an increase in electricity NEGA credits. For a full understanding of this deviation, however, a more thorough sectoral decomposition would be required.

The Czech Republic illustrates an interesting example of how legislative changes can alter the development. While the country has always been a net exporter of embodied energy, the relatively high carbon intensity (at least compared to the world average) led to EXTRA penalties well into 2002 [53]. The newly acquired membership of the EU with its legislative pressures on efficiency improvements and the further expansion of volumes of the Czech exports, led to an increase in the absolute levels of NEGA credits. This transition from EXTRA penalties to NEGA credits of the Czech exports was also driven by the declining share of coal-fired electricity production. Between 1995 and 2009, the share of coal in electricity generation in the Czech Republic declined from 74 to $59 \%$.

China and the USA represent counterparts to much of the European countries. China, as Figure 4 illustrates, had on the whole carbon efficiency of its exports below the world average level throughout the period of study, which can be seen from the constantly negative NEGA credits. The contribution of the carbon-intensive electricity production to this negative trend in China is relatively high and averages at $50 \%$ of the total EXTRA penalties. In the USA, on the other hand, a period of positive NEGA credits can be seen between 1998 and 2004 which is likely a result of fuel-switching from coal to gas; however, a more thorough sectoral decomposition would be needed to explain this sudden and short-lived increase. Otherwise, the pattern of development of the NEGA emissions for the USA identifies carbon efficiency of its exports below the world average level as was in case of China. In the USA, this negative trend is further accentuated by substantial NEGA penalties originating in the electricity sector after 2007.

\subsection{Sectoral Differences}

Throughout the period of study, Sweden had a comparative carbon advantage in majority of its export sectors, both before the credits from the electricity generation were redistributed but also including electricity credits. Figure 5 below summarizes the development in comparative carbon advantage of Swedish export sectors relative to the world average in 2008. Of the total 35 productive exports including in our dataset, Sweden had a comparative carbon advantage in 31 of them. The sectors where Sweden scored below the world average were the agriculture, construction, water transport and sale, maintenance and repair of motor vehicles. Overall, throughout the full period of study, Sweden had a comparative carbon advantage in a vast majority of its export sectors. This means that exports from these 31+ sectors actively contributed to increased global 'welfare' as they reduced the global carbon emissions. Should the same volumes of goods be produced elsewhere using world average technology, the total stock of carbon emissions would increase at a faster pace. 


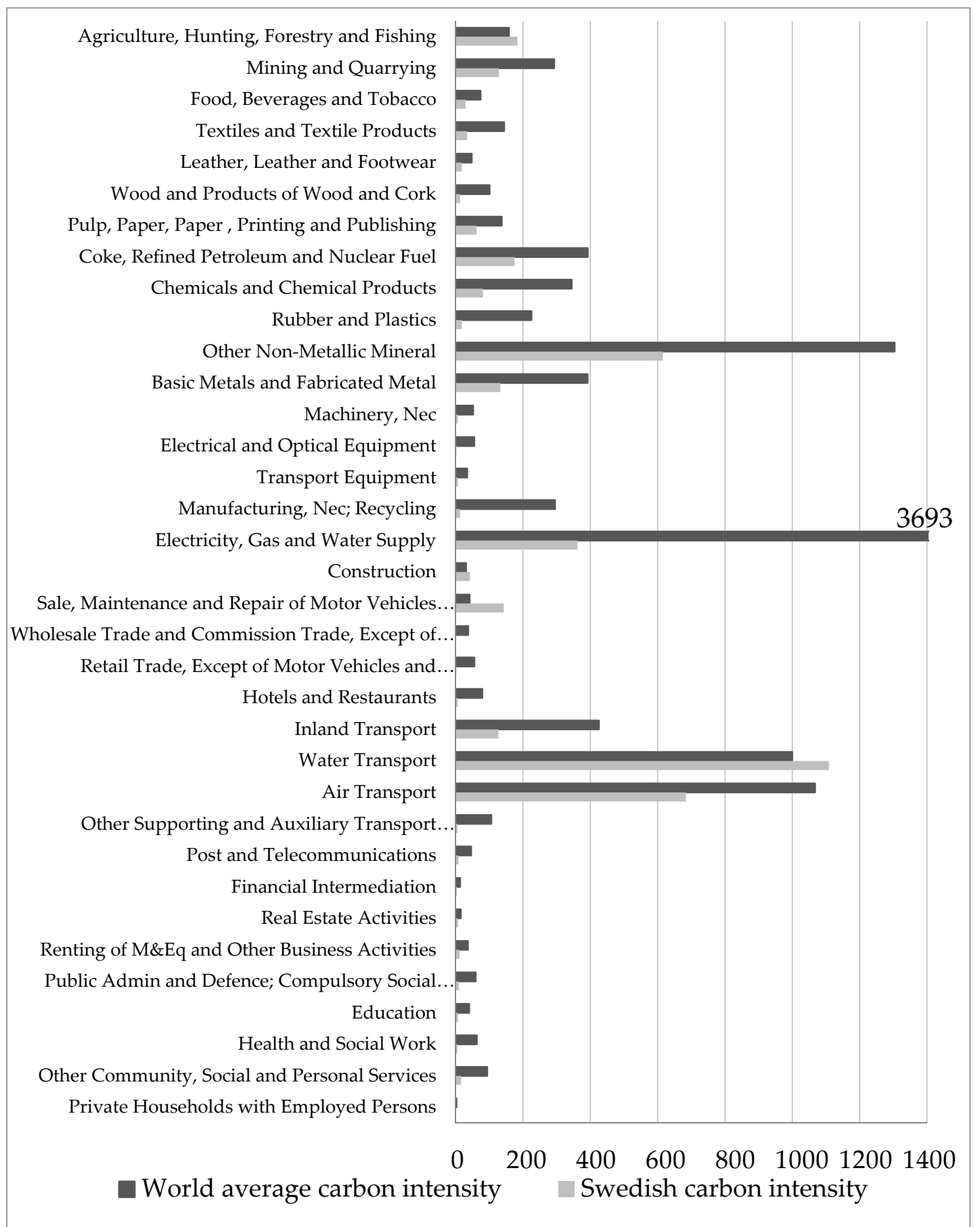

Figure 5. Swedish carbon intensity $\left(\mathrm{CO}_{2} / \$\right.$ of production, in green) v. world average (grey) in 2008 .

What is important, however, is to assess the relative development when compared to the world-average. Are there sectors whose comparative carbon advantage further improved or deteriorated? Does Sweden's overall comparative carbon advantage improve or is the rest of the world catching-up? To illustrate the dynamics of the development in carbon intensity of the Swedish production compared to the rest of the world, a visualization of the average annual changes (in \%) in the sectoral carbon intensity for Sweden and for the world average can be seen in Figure 6 . The grey shaded area of the graph shows sectors that on average increased its carbon intensity compared to the world average between 1995 and 2009 (an outcome less desired), while the rest of the area captures all sectors which lowered its carbon intensity during the period of study. On the positive side it can be 
seen that for the world average the average annual rate of change in carbon intensity was negative, thus indicating a decline in carbon intensity. Also, the average rate of change in carbon intensity of world exports was substantial at nearly $7 \%$ decline annually within the period of study. On the other hand, a more thorough inspection of the Swedish developments shows some less desirable developments. First, five Swedish export sectors increased its carbon intensity (compared to the world average where, in fact, no export sector recorded an increase in carbon intensity). Second, the average rate of decline in carbon intensity was somewhat slower and below that of the world average at $4 \%$ annually. This does not imply that Swedish carbon efficiency in exports is deteriorating, but this rather illustrates that the rest of the world is catching up (especially, as majority of world export sectors is improving faster).

Of the absolute total of 590 million tons of $\mathrm{CO}_{2}$ saved (as NEGA credits), the Swedish exports of steel accounted for the largest share with a contribution at nearly $19 \%$ of total NEGA credits generated between 1995 and 2009 (this is including primary energy combustion as well as electricity embodied in final produce). The other important sectors were the chemicals $(12 \%$ of the total of cumulative NEGA credits), pulp and paper (7.1\%) and electricity (8\%) (Table 1). Here electricity relates only to exports of electricity where electricity is the final product and not electricity embodied in exports of other goods. To focus more on the five sectors which accounted for the largest share of Swedish NEGA credits between 1995 and 2009, the picture draws more positive findings though. For four of the sectors (basic metals, paper and pulp, transport equipment, and machinery) the annual rate of change in carbon intensity decline was relatively fast in Sweden, somehow on par with the rest of the world (see preceding Figure 6). This would imply that although rest of the world is catching up in terms of carbon efficiency, Sweden continues to improve the carbon efficiency of its production and exports in a similar pace. This is a rather remarkable development taking into account that efficiency improvements become progressively exhausted and given the already initially low carbon intensity of Swedish production in mid-1990s. Obviously, the rest of the world has far more space to exploit existing efficiency enhancements and the rate of decline can often be very rapid. Only one sector, the chemicals, recorded far slower rate of decline in carbon intensity in Sweden than the rest of the world. This implies that the rest of the world was more successful in catching up, though the carbon intensity is still far higher than in Sweden even by 2009. One issue that could potentially effect this development is the difference in the composition of the output of the chemical sector between Sweden and the rest of the world. Much of the Swedish exports of chemicals constituted of pharmaceuticals (high in value), while the rest of the world produced particularly bulk chemicals such as acids (low in value and with substantial potential for economies of scale).

Electricity derived NEGA credits (electricity embodied in exported goods) accounted for a total of $26-28 \%$ of Swedish NEGA credits. The sectoral distribution of the electricity NEGA credits differed substantially across each productive sector and had various impacts on the total volume of electricity NEGA credits (see Table 1 for benchmark years and Figure 7 for visualization of the annual development). Table 1 reports the results of the relative contribution of electricity derived NEGA credits to the total sectoral NEGA credits. The contribution of low-carbon electricity in basic metals (19\%) is, for example, far more limited than in the paper and pulp sector (70\%), due to the sector's dependence on coke, a coal-based reduction agent. Traditionally coke has been used as a reduction agent in the production of pig iron from iron ore [52] and is a necessary production input without, at the moment, any potential substitute (recently, research effort has been concentrated into carbon-free substitutes as a reduction agent. In June 2017, a new joint-venture formed by SSAB, LKAB and Vattenfall was created to continue to drive the research into fossil-free steel. The three companies will attempt to develop a steelmaking process that emits water instead of carbon). A more detailed analysis of the major sectors and the contribution of low-carbon electricity in generating a comparative carbon advantage in the world market are discussed in the next subsection. 


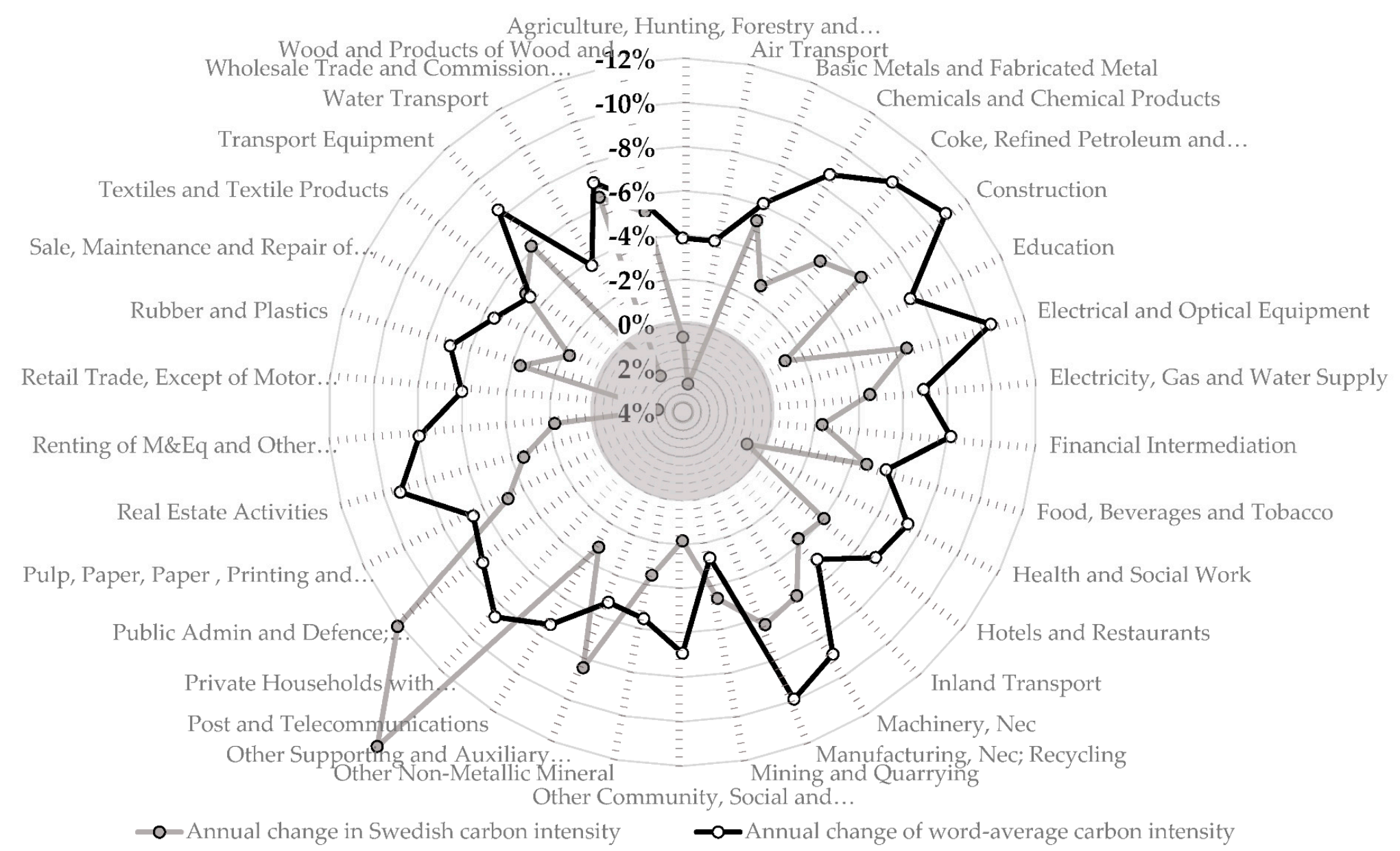

Figure 6. Average annual rate (\%) of change (compound annual growth rate) in sectoral carbon intensity (tons of $\mathrm{CO}_{2} / \$ \mathrm{exports)}$ in $\mathrm{Sweden}$ and the world average. Note: grey shaded circle indicates sectors that experienced an increase in carbon intensity throughout the period 1995-2009. All of these 5 sectors are productive sectors of the Swedish economy. 
Table 1. The sectoral dependence on low-carbon electricity in total NEGA credits (relative share of electricity NEGA credits in total sectoral NEGA credits). Note: Selected sectors only. Exports (\%) relates to percentage share of total Swedish exports in respective year (measures in monetary values).

\begin{tabular}{|c|c|c|c|c|c|c|c|c|}
\hline & $\begin{array}{l}\text { Total Cumulative } \\
\text { NEGA Credits } \\
\text { (Tons } \mathrm{CO}_{2} \text { ) }\end{array}$ & $\begin{array}{c}\text { Of Which } \\
\text { Electricity } \\
\text { Derived NEGA } \\
\text { Credits }\end{array}$ & $\begin{array}{c}\text { Electricity } \\
\text { Credits (\% } \\
\text { Sectoral } \\
\text { NEGA) }\end{array}$ & Exports $(\%)$ & $\begin{array}{c}\text { Electricity } \\
\text { Credits (\% } \\
\text { Sectoral } \\
\text { NEGA) }\end{array}$ & Exports (\%) & $\begin{array}{c}\text { Electricity } \\
\text { Credits }(\% \\
\text { Sectoral } \\
\text { NEGA) } \\
\end{array}$ & Exports (\%) \\
\hline Pulp, Paper, Paper, Printing and Publishing & $42,900,000$ & $30,022,000$ & $70 \%$ & $10 \%$ & $74 \%$ & $9 \%$ & $67 \%$ & $7 \%$ \\
\hline Transport Equipment & $14,980,000$ & $8,173,000$ & $61 \%$ & $15 \%$ & $58 \%$ & $13 \%$ & $54 \%$ & $12 \%$ \\
\hline Machinery, Nec & $15,296,000$ & $6,526,000$ & $45 \%$ & $12 \%$ & $40 \%$ & $11 \%$ & $42 \%$ & $11 \%$ \\
\hline $\begin{array}{l}\text { Wholesale Trade and Commission Trade, } \\
\text { Except of Motor Vehicles and Motorcycles }\end{array}$ & $10,536,000$ & $4,417,000$ & $45 \%$ & $2 \%$ & $46 \%$ & $2 \%$ & $39 \%$ & $3 \%$ \\
\hline Wood and Products of Wood and Cork & $12,748,000$ & $5,416,000$ & $45 \%$ & $4 \%$ & $41 \%$ & $3 \%$ & $47 \%$ & $2 \%$ \\
\hline Electrical and Optical Equipment & $19,695,000$ & $5,859,000$ & $31 \%$ & $13 \%$ & $27 \%$ & $14 \%$ & $35 \%$ & $11 \%$ \\
\hline Renting of M\&Eq and Other Business Activities & $16,774,000$ & $5,406,000$ & $31 \%$ & $5 \%$ & $30 \%$ & $9 \%$ & $37 \%$ & $10 \%$ \\
\hline Textiles and Textile Products & $2,684,000$ & $1,022,800$ & $30 \%$ & $1 \%$ & $39 \%$ & $1 \%$ & $40 \%$ & $1 \%$ \\
\hline $\begin{array}{l}\text { Retail Trade, Except of Motor Vehicles and } \\
\text { Motorcycles; Repair of Household Goods }\end{array}$ & $9,665,000$ & $3,801,000$ & $27 \%$ & $1 \%$ & $29 \%$ & $1 \%$ & $50 \%$ & $2 \%$ \\
\hline Basic Metals and Fabricated Metal & $109,750,000$ & $19,010,000$ & $19 \%$ & $9 \%$ & $18 \%$ & $8 \%$ & $19 \%$ & $9 \%$ \\
\hline Chemicals and Chemical Products & $71,340,000$ & $12,610,000$ & $17 \%$ & $8 \%$ & $17 \%$ & $9 \%$ & $21 \%$ & $8 \%$ \\
\hline Rubber and Plastics & $17,454,000$ & $2,859,000$ & $16 \%$ & $2 \%$ & $14 \%$ & $2 \%$ & $21 \%$ & $2 \%$ \\
\hline Other Non-Metallic Mineral & $17,283,000$ & $1,800,000$ & $15 \%$ & $1 \%$ & $13 \%$ & $1 \%$ & $7 \%$ & $1 \%$ \\
\hline Manufacturing, Nec; Recycling & $20,567,000$ & $2,194,000$ & $13 \%$ & $2 \%$ & $8 \%$ & $2 \%$ & $11 \%$ & $2 \%$ \\
\hline Coke, Refined Petroleum and Nuclear Fuel & $25,554,000$ & $2,058,000$ & $8 \%$ & $2 \%$ & $7 \%$ & $2 \%$ & $9 \%$ & $5 \%$ \\
\hline Others & $181,379,580$ & & & $14 \%$ & & $15 \%$ & & $16 \%$ \\
\hline Total & $588,605,580$ & & $27 \%$ & $100 \%$ & $26 \%$ & $100 \%$ & $28 \%$ & $100 \%$ \\
\hline
\end{tabular}




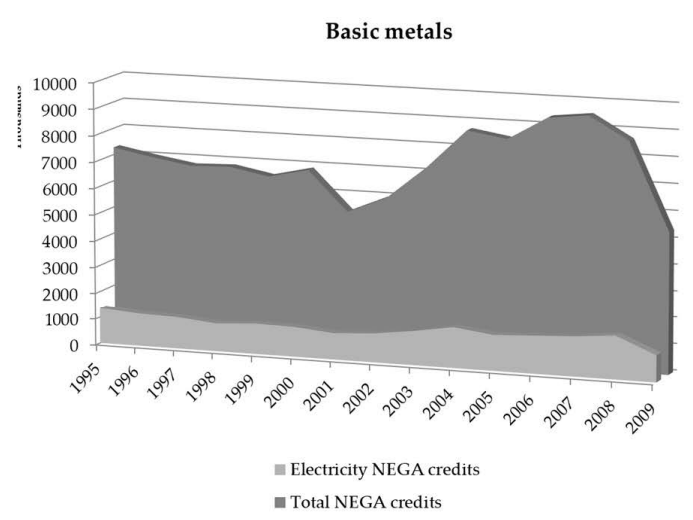

Chemicals

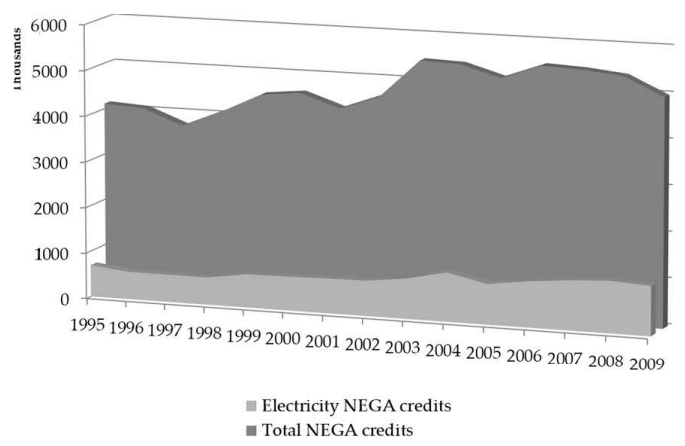

Pulp and paper

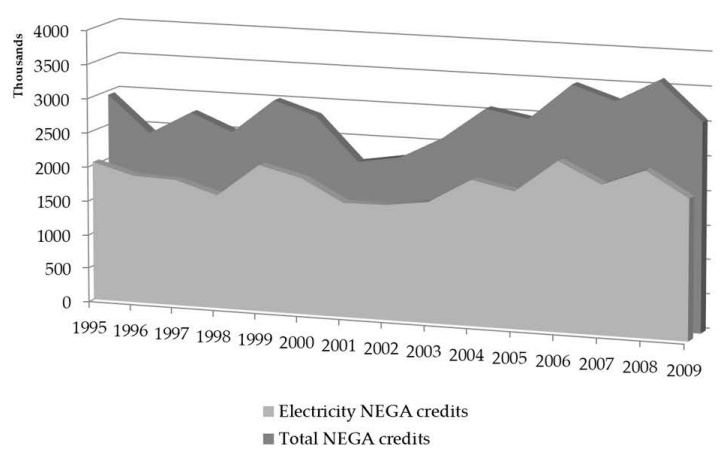

Transport equipment

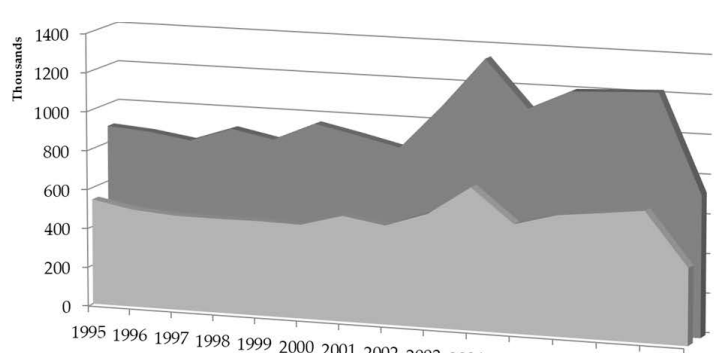

199519961997199819992000200120022003200420052006200720082009

Electricity NEGA credits - Total NEGA credits

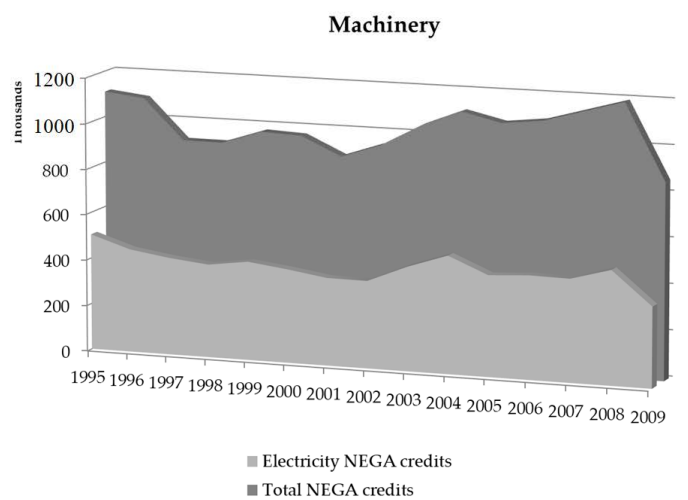

Figure 7. Total NEGA credits in the exports of the Swedish manufacturing sectors, of which NEGA credits derived from the electricity consumption (in tons of $\mathrm{CO}_{2}$ ).

The Swedish paper and pulp sector has undergone a substantial transformation in terms of energy efficiency after being hit by the oil crisis in 1973. This has led to reductions in the sectoral consumption of oil and increased deployment of electricity [54]. The shift towards mechanical pulp production (as opposed to the traditional Kraft pulp production in other producing countries) led to increased electricity intensity of sector. Mechanical pulp production allowed for increases in the wood yield and further refining of the pulp, which over time required increased electricity use [54]. The paper and pulp sector accounted, in relative as well as absolute terms, for the largest share of NEGA credits from low-carbon electricity production.

Overall, 21\% of all NEGA credits from the electricity sector were embodied in the exports of paper and pulp sector. The sector's electricity intensity was also one of the highest as more than $70 \%$ of absolute sectoral NEGA credits could be traced back to the deployment of the low carbon electricity. The share of the sector in the volume of Swedish exports was also relatively high, though it diminished 
from 10 to 7\% between 1995 and 2008. Consequently, this decline in the export share has also led to declines in the relative shares of the electricity NEGA credits of the sector from $21 \%$ in 1995 to $18 \%$ in 2008. Despite that, however, the Swedish paper and pulp sector remains the largest supplier of embodied NEGA credits from the electricity sector. Given the high share of electricity NEGA credits and its importance for the Swedish exports, the paper and pulp sector thus represents one of the largest potential contributors for further exploitation of the comparative carbon advantage of the Swedish electricity. The sector accounted for a total of 42.9 million tons of $\mathrm{CO}_{2} \mathrm{NEGA}$ credits accumulated over a period of 1995 to 2009, which corresponds to more than 7\% of all Swedish NEGA credits and $20 \%$ of all electricity NEGA credits. These are virtually emissions which have been saved globally by having the paper and pulp production located in Sweden and utilizing Swedish low-carbon electricity.

Figure 7 illustrates the large share of electricity derived NEGA credits in the absolute levels of NEGA credits from the pulp and paper exports, and their development between 1995 and 2009, as well as for other significant sectors. The increase in the absolute volume of NEGA credits from the sector was driven by the increase of the volumes exported (in monetary terms), though this was to some extent offset by the decline in the NEGA credits per output ( $\mathrm{M}$ ton $\mathrm{CO}_{2} / \mathrm{bil}$. USD). While in 1995, one million of USD of paper and pulp exports generated 290 tons of $\mathrm{CO}_{2}$ credits, this has declined to less than 230 tons of $\mathrm{CO}_{2}$ saved on the global market by 2008. This change in the relative contribution of the Swedish NEGA export intensity does not necessarily mean that Swedish paper and pulp's efficiency is deteriorating. Rather, it implies that the state of the world average technology is improving at a faster rate than that of Sweden.

The relative contribution of low-carbon electricity for the basic metals sector was one of the lowest among other manufacturing sectors. This is almost entirely due to the production specifics of the sector where the potential use of electricity is currently relatively low. Much of the NEGA credits generated by the sector (and those are indeed substantial) are a result of efficient production process compared to the world average. At the same time the low utilization of electricity in the sector represents one of the largest and most substantial potentials in further increasing the Swedish NEGA credits-and that is through increased electrification of the sector. Swedish Energy Agency is therefore investing heavily in project of carbon-free electricity where hydrogen (produced with the use of Swedish low carbon electricity) is used as a reduction agent. Clearly, if the results of the project prove its feasibility, this would be a path-breaking development having a huge impact on the absolute levels of Swedish carbon emissions (in Sweden, 20\% of emissions embodied in Swedish exports are not energy-related but rather a result of industrial processes, in particular in the steel and cement industry).

The chemical sector is the third largest user of industrial energy in Sweden, accounting for a total of $9 \%$ of industrial energy use. Here, electricity is used mainly for electrolysis processes and any further electrification of the sector is conditioned by the type of output produced. Overall, the contribution of low carbon electricity to total NEGA credits was relatively low at around $9 \%$ in 2008 . The sector is, as the iron and steel sector, characterized by the use of fossil energy for non-energy purposes, mainly in the form of raw materials. Much of the potential for this sector to reduce its carbon emission therefore lies in the use of alternative raw materials (new bio-based chemicals) and in the storage of carbon emissions. Currently, there are pilot projects in Sweden whose aim is to engineer bio-based chemicals and plastics by replacing traditional fossil fuels as raw materials in the production.

The relative contribution of low-carbon electricity in the exports of transport equipment and machinery was fairly high given the high utilization of electricity in the production process. Overall, the sector is not regarded as energy intensive, though given the high proportion of Sweden's total industrial output as well as exports, the engineering sector accounts for relatively high share of industrial energy use (and also the NEGA credits).

\subsection{Does Sweden Trade According to Its Comparative Advantage?}

In Jiborn et al. [52] a new decomposition method was introduced to capture the degree and potentially a loss of the comparative carbon advantage of Sweden (and the UK). The researchers find, 
first, that even though Swedish carbon intensity of exports continued its decline throughout the period of study, the relative comparative carbon advantage has diminished as the rest of the world has been catching-up at a faster pace-a similar finding also in this paper. Second, the export structure of the country has become less carbon intensive while the import structure more carbon intensive, pointing out to some potential of emissions displacement [52]. This supports the finding that Sweden has reduced domestic emissions, at least partly, by reorienting domestic production structure towards less carbon intensive goods and imports towards more carbon intensive goods [52]. So Sweden has not only lost some of its comparative carbon advantage between 1995 and 2009, it has also somehow reduced the exploitation of this advantage in relative terms (though not in absolute levels).

A visualization of the average annual rate of change in exports is shown in Figure 8. The graph pinpoints all export sectors of Sweden against the average rate of change in their respective carbon intensity between 1995 and 2009. The upper left area of the graph highlights the most desirable situation, where ideally most Swedish sectors would be located-those are sectors which achieved above average improvements in carbon intensity while at the same time growing fastest in terms of relative export volumes. To have a desired impact on the global climate, it would therefore make most sense if these sectors were those exploited the most. Yet, many of the traditional manufacturing sectors (such as basic metals, paper and machinery) have, despite substantial declines in carbon intensity, grown exports at a below the average growth rate. Meanwhile, one of the largest export sectors with substantial declines in carbon intensity was the 'Other supporting and auxiliary transport activities' sectors. This service sector is basically a support of the transport sector and entails cargo handling services, storage and warehouse services and others (WTO definition). Its significance in the export shares as well as growth is subsequently a natural consequence of Sweden's growth in exports and the growing need for transport support services.

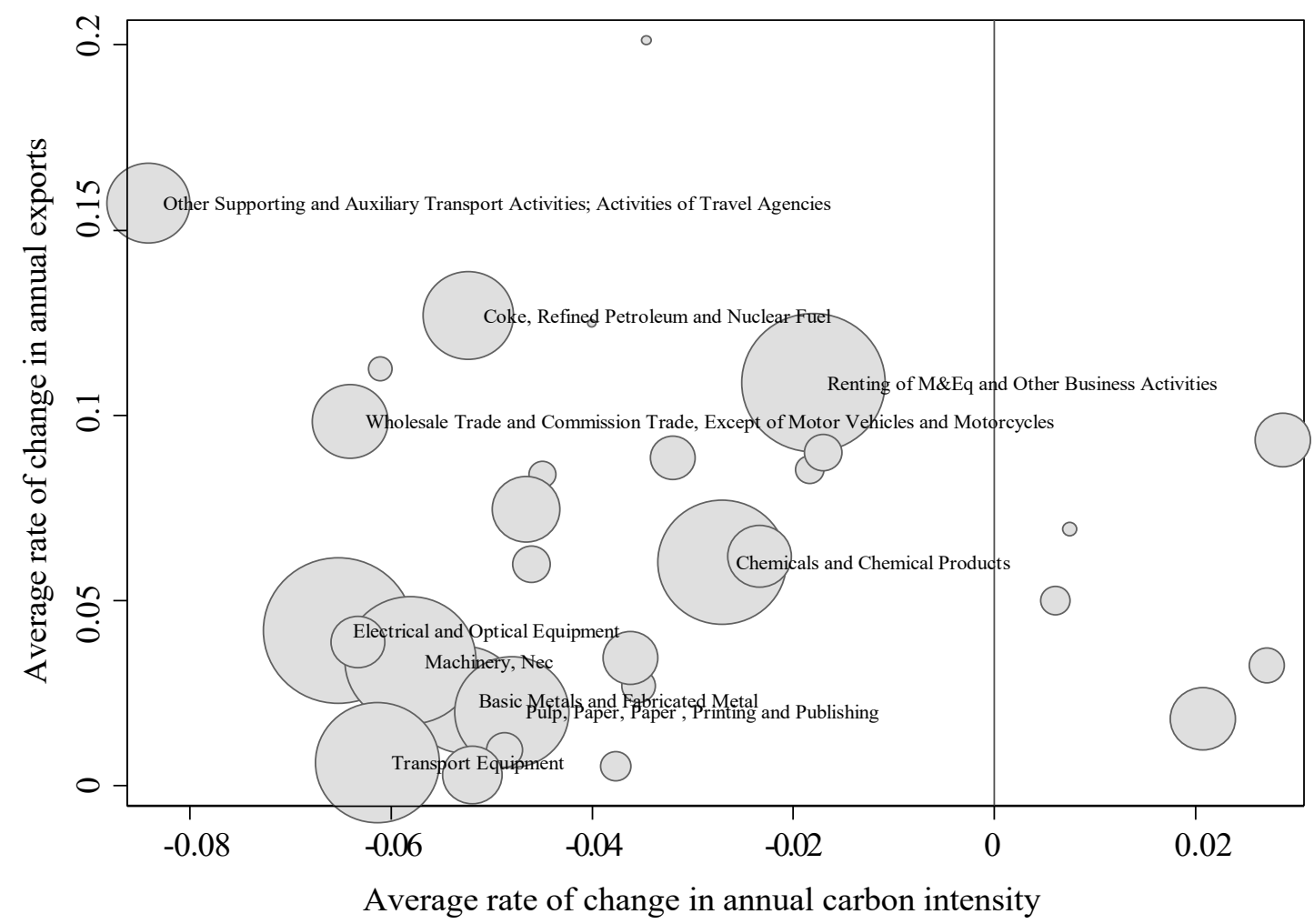

Figure 8. Average annual rate of change in carbon intensity versus change in annual export volumes. Note: The size of the circle indicates the relative share of the sector in total exports in 2009. Area in the left-hand side of the graph refers to the most desirable situation with increasing exports in sectors with falling carbon intensity. Area on the right-hand side denotes the opposite, suboptimal situation, with increasing exports from sectors with growing carbon intensity. 


\section{Discussion and Wider Policy Implications}

At a national level, electricity sectors are undergoing fundamental changes [55]. The diffusion of new renewable energy sources such as wind, solar or biomass has escalated in the last decade in countries such as China, the United States, Germany or India, while in some countries renewables already supply a substantial share of the power generation [55]. The ongoing transition of the electricity system, however, faces some major challenges such as changing role of public policies, new players in the arena, the integration of multi-technology interactions and uncertainty or re-configuration of the entire sector/system (ibid). Yet, what much of the transition and innovation scholars have in common is the focus on the implications at the country level and the impact of renewable energy system changes on the national policies and targets. It has become clear that global forces increasingly interact also with 'local policies, institutional contexts and infrastructures' and research into how 'local transition pathways connect and accumulate into global ones' is highly desirable $[55,56]$.

The method of this paper suggests and empirically tests how the transition to an economy fueled by low-carbon electricity offers a solution to the decarbonisation, not only at a national scale but also at a global level by lowering the carbon content embodied in traded goods. The empirical evidence in this paper, the discussion and conclusion, is based on a case study of the Swedish economy over a period 1995-2008. The results show how increased investments into low-carbon electricity production underestimate the global gains in terms of emission reductions, because of the cross-border spillovers of direct electricity exports and exports of electricity embodied in manufactured goods. This commonly overseen aspect of low-carbon electricity production requires further attention not only for the purposes of the global decarbonisation but also for the design and implementation of future emission trading schemes, pricing or cross-border adjustments. Understanding the spillover effects of renewable electricity investment, helps to provide enhanced information and guide policymakers to think systematically about the interactions of these investments at the national as well as the global level. Overall, throughout the period of study, Sweden maintained its absolute and comparative carbon advantage in a majority of its export sectors, though the gap between the Swedish and world carbon efficiency narrowed within this period. Sweden had an absolute carbon advantage in 31 out of its 35 productive sectors. While the country had an absolute carbon advantage in majority of its sectors, it also had a comparative carbon advantage in many sectors, though the magnitude of the welfare gains differed largely. Under the assumption that involvement in foreign trade leads to static welfare gains of trade, which within this paper translate into savings of global carbon emissions, then the comparatively largest contributors to these welfare gains are three productive sectors of the Swedish economy accounting for close to $40 \%$ of total welfare gains: basic metals, chemicals and pulp and paper. The role of electrification of the Swedish industry has brought, to some extent, this comparative carbon advantage. Particularly sectors such as paper and pulp hugely benefited from this technological transition that commenced as early as 1970s. But the potential for further electrification of the Swedish industry is far from exhausted. The electricity-fueled hydrogen-based steel production is currently under testing and the potential for the substitution of fossil fuels through bio-based alternatives in the production of chemicals could have a substantial impact. Although with the ongoing structural change in the Swedish exports, this might have a limited impact on the overall levels of NEGA credits in the future, the electrification of particularly the steel and chemicals sector could have a huge impact on the overall Swedish comparative carbon advantage. In the past, the carbon efficiency of Swedish exports was higher than the world average, though the fast average annual rate of change in the world manufacturing did lower this efficiency gap to a certain degree. There are several ways in which countries like Sweden with comparative carbon advantage can further exploit and increase the volumes of emissions savings. Swedish companies can, for example, more pro-actively market its produce abroad with an environmental disclosure. Companies, public bodies and other institutions can also use the comparative carbon advantage to attract foreign investments, particularly investments with high electricity consumption. By relocating (part) of its production to countries like Sweden, other foreign firms can indeed lower the carbon footprint of their produce and indeed actively contribute to the 
global mitigation efforts. The concept of comparative carbon advantage can thus have some profound policy implications and can be used as a climate mitigation tool.

Last one also has to keep in mind that wider cross-country adoption of the similar mechanisms as evidenced in the case of Sweden will have some profound impacts on the world-average carbon intensity. Since the concept of comparative carbon advantage is based on the relative measure to world-average carbon intensity, any significant improvement in the world average will inevitably lead to lower NEGA credits, or potential emissions savings. This does not mean that the respective country is increasing carbon intensity of its production, but that the world on average is catching up faster. This trend is already evident within this paper as the average annual rate of change in world-average carbon intensity is faster than that of Sweden. Countries at the frontier of energy and carbon efficiency have usually less space for improvement than laggards where often simple and less costly measures can have a substantial impact on carbon intensity of production. Previous research has also shown that while deployment of best available technology can potentially reduce the energy intensity by up to $25 \%$, there is also a limit for maximum energy efficiency. Once more countries adopt best available technology, the possibility to exploit further the NEGA credits will become exhausted. This is when investments into low-carbon electricity production and increased electrification of the major energy-intensive processes could be one of the potential drivers of future NEGA credits.

A question arises to what degree this concept is then applicable to other countries, often countries without the state-of-art production techniques or in the absence of decarbonized electricity system and stringent environmental legislation. The evidence of Sweden has shown that in order to fully exploit the comparative advantage, there needs to be strong and mutual synergies of both best available technology adoption and low-carbon electricity. Globally, low carbon electricity (including nuclear energy) accounted for $34 \%$ of total electricity production, but cross-country differences (this is irrespective the level of development with some of the most developed countries such as Japan having a highly carbon-intensive electricity generation, while on the other hand certain developing countries such as Brazil with more than $75 \%$ share of low-carbon electricity (mainly hydropower)) remain large and range between 10 and well over $90 \%$ of the national electricity production [57]. Investments into renewables or fuel switching away from carbon intensive electricity production would positively impact the countries' position in respect to comparative carbon advantage. This move would, however, need to be accompanied by continuous adoption of best available technology, which for some countries would lead to increased costs of production, particularly in the absence of global carbon prices.

\section{Conclusions}

Decoupling of carbon emissions from economic growth is at the heart of future sustainable transitions. Several mechanisms have been proposed as the major drivers decoupling, including increased energy and carbon efficiency of production and the decarbonisation of the electricity generation. Yet, while certain countries continuously intensify its decarbonisation efforts, there is a danger that emission reductions in regulated countries with clear absolute reduction targets become offset or even exceeded by emission increases in unregulated areas or areas with only relative carbon reduction targets.

In an increasingly globalized world, trade has often been seen as a driver of decoupling of carbon emissions from economic growth in the developed world, while increasing carbon emissions in the least developed parts of the world. Yet, most theoretical propositions of this trend of outsourcing lack empirical evidence or the existing evidence is based on methods which disregard cross-country differences in carbon intensity of production. Under such assumptions, a highly carbon efficient country which trades identical goods with an unregulated country with obsolete technology will always be treated as a country outsourcing its polluting production abroad.

The major aim of this study was to assess to what extent the outsourcing theories hold when national differences in carbon intensity are taken into account. The paper explores a hypothesis that countries with highly carbon efficient production and low-carbon electricity system will change its position from being the outsourcer of emissions to, in fact, providing additional emissions savings as a 
results of its involvement in the global trade. On the other hand, other countries, sometimes referred to as the workshops of the world, with carbon intensive production and coal-based electricity generation, will be penalized for not having cleaned

The paper uses environmentally-extended input-out tables of Sweden for the period 1995-2009 and calculates the technologically-adjusted consumption-based (TCBA) emissions accounts. The method then compares Sweden's carbon efficiency to the newly calculated measure of 'world-average' technology. World-average technology is a technology of production available for respective sector and year by taking into account sectoral carbon intensity of the world. Compared to other studies using the established TCBA, the method further redistributes $\mathrm{CO}_{2}$ emissions from the electricity generation sector, which makes it possible to distinguish and quantify the impact of two major decarbonisation mechanisms: carbon efficiency of production and low-carbon electricity generation.

The paper specifically studies the role of productive efficiency and decarbonized energy system applied on the case of Sweden and its impact on the embodied emissions in its trade. Having both an energy efficient production and low-carbon electricity network was found to be an important mechanism behind this advantage in the global trade arena. Overall, by Sweden exporting its production globally between 1995 and 2009, Sweden contributed nearly 590 million tons of $\mathrm{CO}_{2}$ potential savings through its exports by having an efficient and low-carbon production. Furthermore this report analyzes and quantifies the contribution of low-carbon electricity generation to Sweden's comparative carbon advantage. Low carbon electricity generation accounted for over $34 \%$ of the total savings, of which some $20 \%$ were direct exports of electricity and $80 \%$ was electricity embodied in exported products. The three productive sectors, which accounted for the largest shares of electricity derived NEGA credits were the paper and pulp, the basic metals and the chemical sectors. The role of electricity embodied in the exported goods (and services) is thus substantial and an important contributor to Sweden's comparative carbon advantage.

Author Contributions: Conceptualization, H.N. and A.K.; Formal analysis, H.N.; Funding acquisition, H.N. and A.K.; Investigation, H.N.; Resources, A.K.; Supervision, A.K.; Visualization, H.N.; Writing-original draft, H.N. and A.K.; Writing-review \& editing, H.N. All authors have read and agreed to the published version of the manuscript.

Funding: This research was partially funded by Energiforsk grant number 2018:497. The APC was funded by Handelsbanken grant number W17-0025.

Conflicts of Interest: The authors declare no conflict of interest. The funders had no role in the design of the study; in the collection, analyses, or interpretation of data; in the writing of the manuscript, and in the decision to publish the results.

\section{References}

1. Kander, A.; Malanima, P.; Warde, P. Power to the People: Energy in Europe over the Last Five Centuries; Princeton University Press: Princeton, NJ, USA, 2013.

2. Henriques, S.T.; Kander, A. The modest environmental relief resulting from the transition to a service economy. Ecol. Econ. 2010, 70, 271-282. [CrossRef]

3. World Trade Organization. Trends in International Trade; World Trade Organization: Geneva, Switzerland, 2013.

4. Peters, G.P.; Minx, J.C.; Weber, C.L.; Edenhofer, O. Growth in emission transfers via international trade from 1990 to 2008. Proc. Natl. Acad. Sci. USA 2011, 108, 8903-8908. [CrossRef] [PubMed]

5. Jakob, M.; Marschinski, R. Interpreting trade-related $\mathrm{CO}_{2}$ emission transfers. Nat. Clim. Chang. 2012, 3 , 19-23. [CrossRef]

6. Jiborn, M.; Kulionis, V.; Kander, A. Consumption versus technology: Drivers of global carbon emissions 2000-2014. Energies 2020, 13, 339. [CrossRef]

7. Szigeti, C.; Toth, G.; Szabo, D.R. Decoupling - shifts in ecological footprint intensity of nations in the last decade. Ecol. Indic. 2017, 72, 111-117. [CrossRef]

8. Suri, V.; Chapman, D. Economic growth, trade and energy: Implications for the environmental Kuznets curve. Ecol. Econ. 1998, 25, 195-208. [CrossRef] 
9. Ghertner, D.A.; Fripp, M. Trading away damage: Quantifying environmental leakage through consumptionbased, life-cycle analysis. Ecol. Econ. 2007, 63, 563-577. [CrossRef]

10. Weber, C.L.; Peters, G.P.; Guan, D.; Hubacek, K. The contribution of Chinese exports to climate change. Energy Policy 2008, 36, 3572-3577. [CrossRef]

11. Pan, J.; Phillips, J.; Chen, Y. China's balance of emissions embodied in trade: Approaches to measurement and allocating international responsibility. Oxf. Rev. Econ. Policy 2008, 24, 354-376. [CrossRef]

12. Healy, S.; Schumacher, K.; Eichhammer, W. Analysis of Carbon Leakage under Phase III of the EU Emissions Trading System: Trading Patterns in the cement and aluminium sectors. Energies 2018, 11, 1231. [CrossRef]

13. Geels, F.W. The multi-level perspective on sustainability transitions: Responses to seven criticisms. Environ. Innov. Soc. Transit. 2011, 1, 24-40. [CrossRef]

14. Grübler, A. Energy transitions research: Insights and cautionary tales. Energy Policy 2012, 50, 8-16. [CrossRef]

15. Mulder, P.; de Groot, H.L.F. Sectoral Energy- and Labor-Productivity Convergence; Tinbergen Institute: Amsterdam, The Netherlands, 2004.

16. Mulder, P. International Specialization, Sector Structure and the evolution of manufacturing energy intensity in OECD countries. Energy J. 2015, 36, 111-136. [CrossRef]

17. Schandl, H.; West, J. Resource use and resource efficiency in the Asia-Pacific region. Glob. Environ. Chang. 2010, 20, 636-647. [CrossRef]

18. Fischedick, M.; Roy, J.; Abdel-Aziz, A.; Acquaye, A.; Allwood, J.M.; Ceron, J.-P.; Geng, Y.; Kheshgi, H.; Lanza, A.; Perczyk, D. Industry. In Climate Change 2014: Mitigation of Climate Change. Contribution of Working Group III to the Fifth Assessment Report of the Intergovernmental Panel on Climate Change; Edenhofer, O., Pichs-Madruga, R., Sokona, Y., Farahani, E., Kadner, S., Seyboth, K., Adler, A., Baum, I., Brunner, S., Eickemeier, P., et al., Eds.; Cambridge University Press: Cambridge, UK, 2014.

19. Hübler, M.; Löschel, A. The EU decarbonisation roadmap 2050—What way to walk? Energy Policy 2013, 55, 190-207. [CrossRef]

20. Lechtenböhmer, S.; Nilsson, L.J.; Åhman, M.; Schneider, C. Decarbonising the energy intensive basic materials industry through electrification - Implications for future EU electricity demand. Energy 2016, 115, 1623-1631. [CrossRef]

21. Schumacher, R. Free Trade and Absolute and Comparative Advantage; Universität Potsdam: Potsdam, Germany, 2012.

22. OECD. Globalisation, Comparative Advantage and the Changing Dynamics of Trade; OECD Publishing: Paris, France, 2011; Volume 2011.

23. Broner, F.; Bustos, P.; Carvalho, V.M. Sources of Comparative Advantage in Polluting Industries; National Bureau of Economic Research: Cambridge, MA, USA, 2011.

24. World Bank. State and Trends of Carbon Pricing 2019; The World Bank: Washington, DC, USA, 2019. [CrossRef]

25. Nordhaus, W. Climate Clubs: Overcoming free-riding in international climate policy. Am. Econ. Rev. 2015, 105, 1339-1370. [CrossRef]

26. Pihl, H. A Climate Club as a complementary design to the UN Paris agreement. Policy Des. Pract. 2020, 3, 45-57. [CrossRef]

27. Condon, M.; Ignaciuk, A. Border Carbon Adjustment and International Trade: A Literature Review; OECD: Paris, France, 2013.

28. Kuik, O.; Hofkes, M. Border adjustment for European emissions trading: Competitiveness and carbon leakage. Energy Policy 2010, 38, 1741-1748. [CrossRef]

29. Böhringer, C.; Balistreri, E.J.; Rutherford, T.F. The role of border carbon adjustment in unilateral climate policy: Overview of an Energy Modeling Forum study (EMF 29). Energy Econ. 2012, 34, S97-S110. [CrossRef]

30. Monjon, S.; Quirion, P. A border adjustment for the EU ETS: Reconciling WTO rules and capacity to tackle carbon leakage. Clim. Policy 2011, 11, 1212-1225. [CrossRef]

31. Böhringer, C.; Carbone, J.C.; Rutherford, T.F. The Strategic value of carbon tariffs. Am. Econ. J. Econ. Policy 2016, 8, 28-51. [CrossRef]

32. Böhringer, C.; Rosendahl, K.E.; Storrøsten, H.B. Robust policies to mitigate carbon leakage. J. Public Econ. 2017, 149, 35-46. [CrossRef]

33. von der Leyen, U. Political Guidelines for the Next European Commission; EU: Brussels, Belgium, 2019.

34. Skúlason, J.B.; Hayter, R. Industrial location as a bargain: Iceland and the aluminium multinationals 1962-1994. Geogr. Ann. Ser. B 1998, 80, 29-48. [CrossRef] 
35. Jaffe, A.B.; Peterson, S.R.; Portney, P.R.; Stavins, R.N. Environmental regulation and the competitiveness of U.S. manufacturing: What does the evidence tell us? J. Econ. Lit. 1995, 33, 132-163.

36. Ambec, S.; Cohen, M.A.; Elgie, S.; Lanoie, P. The porter hypothesis at 20: Can environmental regulation enhance innovation and competitiveness? Rev. Environ. Econ. Policy 2013, 7, 2-22. [CrossRef]

37. Porter, J. America's green strategy. Sci. Am. 1991, 264, 168. [CrossRef]

38. Weiss, J.F.; Anisimova, T. The innovation and performance effects of well-designed environmental regulation: Evidence from Sweden. Ind. Innov. 2019, 26, 534-567. [CrossRef]

39. Lindmark, M.; Bergquist, A.K. Expansion for pollution reduction? Environmental adaptation of a Swedish and a Canadian metal smelter, 1960-2005. Bus. Hist. 2008, 50, 530-546. [CrossRef]

40. Bergquist, A.-K.; Söderholm, K. R \& D Collaboration and Environmental Adaptation: A Pilot Study of the Swedish pulp- and Paper Industry 1900-1990. Umeå Papers in Economic History NV-39, 2010; Institutionen för Ekonomisk Historia: Umea, Sweden, 2010.

41. Bergquist, A.-K.; Söderholm, K.; Kinneryd, H.; Lindmark, M.; Söderholm, P. Command-and-control revisited: Environmental compliance and technological change in Swedish industry 1970-1990. Ecol. Econ. 2013, 85, 6-19. [CrossRef]

42. Broberg, T.; Marklund, P.-O.; Samakovlis, E.; Hammar, H. Testing the Porter hypothesis: The effects of environmental investments on efficiency in Swedish industry. J. Product. Anal. 2013, 40, 43-56. [CrossRef]

43. Böhringer, C.; Carbone, J.; Rutherford, T.F. Embodied carbon tariffs. Scand. J. Econ. 2016. [CrossRef]

44. Fujii, H.; Managi, S. Optimal production resource reallocation for $\mathrm{CO}_{2}$ emissions reduction in manufacturing sectors. Glob. Environ. Chang. 2015, 35, 505-513. [CrossRef]

45. Strømman, A.H.; Hertwich, E.G.; Duchin, F. Shifting Trade Patterns as a Means of Reducing Global Carbon Dioxide Emissions A Multiobjective Analysis. J. Ind. Ecol. 2009, 13, 38-57. [CrossRef]

46. Gallego, B.; Lenzen, M. A consistent input-output formulation of shared producer and consumer responsibility. Econ. Syst. Res. 2005, 17, 365-391. [CrossRef]

47. Lenzen, M.; Murray, J.; Sack, F.; Wiedmann, T. Shared producer and consumer responsibility-Theory and practice. Ecol. Econ. 2007, 61, 27-42. [CrossRef]

48. Kander, A.; Jiborn, M.; Moran, D.D.; Wiedmann, T.O. National greenhouse-gas accounting for effective climate policy on international trade. Nat. Clim. Chang. 2015, 5, 431-435. [CrossRef]

49. Springmann, M. Integrating emissions transfers into policy-making. Nat. Clim. Chang. 2014, 4, $177-181$. [CrossRef]

50. Steininger, K.W.; Lininger, C.; Meyer, L.H.; Munoz, P.; Schinko, T. Multiple carbon accounting to support just and effective climate policies. Nat. Clim. Chang. 2016, 6, 35-41. [CrossRef]

51. Grasso, M.; Roberts, T. A compromise to break the climate impasse. Nat. Clim. Chang. 2014, 4, 543-549. [CrossRef]

52. Jiborn, M.; Kander, A.; Kulionis, V.; Nielsen, H.; Moran, D.D. Decoupling or delusion? Measuring emissions displacement in foreign trade. Glob. Environ. Chang. 2018, 49, 27-34. [CrossRef]

53. Nielsen, H. Industrial Intensification and Energy Embodied in Trade: Long-Run Energy Perspective of the Planned Economy of Czechoslovakia. J. Ind. Ecol. 2017, 1-15. [CrossRef]

54. Bergquist, A.-K.; Söderholm, K. Sustainable energy transition: The case of the Swedish pulp and paper industry 1973-1990. Energy Effic. 2016, 9, 1179-1192. [CrossRef]

55. Markard, J. The next phase of the energy transition and its implications for research and policy. Nat. Energy 2018. [CrossRef]

56. Markard, J.; Raven, R.; Truffer, B. Sustainability transitions: An emerging field of research and its prospects. Res. Policy 2012, 41, 955-967. [CrossRef]

57. International Atomic Energy Agency. Transitions to Low Carbon Electricity Systems: Key Economic and Investment Trends; IAEA: Vienna, Austria, 2019.

(C) 2020 by the authors. Licensee MDPI, Basel, Switzerland. This article is an open access article distributed under the terms and conditions of the Creative Commons Attribution (CC BY) license (http://creativecommons.org/licenses/by/4.0/). 